\title{
Sensory systems and feeding behaviour of the giant freshwater prawn, Macrobrachium rosenbergii, and the marine whiteleg shrimp, Litopenaeus vannamei
}

\author{
Gunzo Kawamura1* ${ }^{*}$ Teodora Uy Bagarinao² and Annita Seok Kian Yong1 \\ ${ }^{1}$ Borneo Marine Research Institute, Universiti Malaysia Sabah, 88400 Kota Kinabalu, Sabah, Malaysia \\ ${ }^{2}$ Aquaculture Department, Southeast Asian Fisheries Development Center, Tigbauan, Iloilo, Philippines
}

${ }^{*}$ Corresponding author: prof.gunzo@gmail.com

\begin{abstract}
Information on the sensory basis of shrimp feeding provides the means for assessment of the effectiveness of food items in terms of smell, taste, size, and colour. This chapter summarizes information about the sensory basis of the feeding behaviour of the giant freshwater prawn (Macrobrachium rosenbergii) and the marine whiteleg shrimp (Litopenaeus vannamei). Existing literature on these shrimp species and other decapod crustaceans is reviewed, and unpublished experiments using the selective sensory ablation technique to determine the involvement of vision, chemoreception, and touch sense in the feeding behavior of the juveniles of M. rosenbergii and L. vannamei are also described. To determine the role of vision in feeding, the eyes of the juveniles were painted over (deprived of vision) with white manicure and their feeding response to commercial pellets was compared with those with untreated eyes. The untreated eyed juveniles detected and approached a feed pellet right away, but the specimens blinded by the coating detected a pellet only after random accidental touch with the walking legs while roaming on the aquarium bottom. Juveniles that had learned to feed on pellets showed food search and manipulation responses to a pellet-like pebble without smell and taste. The early larvae (zoeae) of $M$. rosenbergii already have colour vision (that likely persists through life) and colour preference for blue and white. The adults of L. vannamei discriminated a blue-colored well among seven grey wells in a palette, also showing colour vision in this shrimp. A behavioural experiment with dyed prawn flesh showed that $L$. vannamei has innate color preference for yellow food over black, red, green, and blue food regardless of the background colours of the aquarium bottom. To disrupt chemoreception, the juveniles of both the species were abruptly transferred to water of drastically different salinity and the osmotic ablation destroyed the chemosensitive sensilla. The osmotically ablated juveniles approached a pellet right away but failed to ingest it; they had learned the visual cue and texture of the pellets and recognized them by vision and tactile sense. To determine the role of sensory appendages in feeding of $L$. vannamei juveniles, the antennal flagella, antennular flagella, and the pincers of the pereiopods were ablated. The ablated juveniles roamed the bottom, touched a pellet at random, grabbed it with the maxillipeds, and ingested it. Subsequently they learned to lower the head, actively swim forward, sweep the bottom with the maxillipeds, detect a pellet, and ingest it-thus indicating a plasticity in feeding behaviour in L. vannamei.
\end{abstract}

Keywords: Sensory ablation, Colour vision, Chemosense, Touch sense, Conditioning

\section{Introduction}

Animals acquire information about the environment through specialized sensory organs that respond to particular stimuli and they use this information to accomplish behavioural objectives such as feeding, swimming, predator avoidance, net avoidance, or migration (Kawamura et al., 2015).

Feed is normally the largest single expenditure item in the operation of a shrimp farm (Rhodes, 2000). In formulating shrimp feeds, the nutritional quality, palatability, and cost effectiveness are important considerations for commercial success. Nutritional and palatability investigations on shrimp have been confined to empirical dietary trials and the data so generated have elucidated their nutritional requirements and the palatability of feeds (Tantikitti, 2014), including the effect of feed attractants (Yacoob, 2003). However, more research is still necessary, particularly on the feeding behaviour of shrimp.

The first principle of feed development is to know what the animal prefers to eat in the wild. Formulated diets that are well accepted by animals presently require high inclusion ratios of expensive animal protein. Much research has been done to develop less expensive feeds that animals accept and grow well on, including work on acceptability and apparent digestibility of cheaper alternative ingredients, many of them of terrestrial rather than marine origin. A large number of such formulated feeds with different ingredients have been produced and evaluated for effectiveness for farmed shrimps and lobsters (Tacon, 2002; Williams, 2007). Acceptability and digestibility of these feeds have been assessed empirically by computing the feed utilization such 
as feed intake and feed conversion ratio for animals reared over extended periods. However, from such assessment, no information is obtained on what feeds the animals consider pleasant or unpleasant in terms of smell or taste.

Understanding feeding behaviour is also important for feed development. Information on the sensory basis of shrimp feeding provides the means for assessment of the effectiveness of food items in terms of smell, taste, size, and colour. This chapter summarizes information about the sensory basis of the feeding behaviour of decapod crustaceans, particularly the giant freshwater prawn, Macrobrachium rosenbergii (Family Palaemonidae), and the marine whiteleg shrimp, Litopenaeus vannamei (Family Penaeidae). Also described here are the experiments using selective sensory ablation technique (used by many neurophysiologists) to determine the involvement of vision, olfaction, gustation, and touch sense in the feeding behaviour of the juveniles of $M$. rosenbergii and L. vannamei.

\section{Food preference and feeding habits in the wild}

Food preferences of decapod crustaceans in the wild have been determined with several different methods, e.g., analysis of foregut contents in wild captured shrimp, dietary preference in feeding experiments, and capture of the shrimp by traps with various baits.

\section{Macrobrachium rosenbergii}

The larval phase of $M$. rosenbergii consists of 11 pelagic stages of zoea and benthic stages of postlarvae. The larvae of M. rosenbergii can eat any time, not restricted by time of day or night, and their natural food items are principally zooplankton (mainly minute crustaceans), very small worms, and the larval stages of other aquatic invertebrates. As the specimens grow, the natural diet comprises aquatic insect larvae, algae, small fruits and seeds, mollusk larvae, small crustaceans, fish flesh, and the offal of fish and other animals (New, 2002). The digestive enzyme profile of $M$. rosenbergii is that of an omnivore (Lee et al., 1980).

Costa and Wanninayake (1986) examined the gut contents of $M$. rosenbergii sampled from fishery areas in Sri Lanka and found selective feeding on animal matter. To prove selective feeding, gut contents have to be compared with the fauna and flora in the waters where the shrimp were sampled. However, no such data on the natural fauna and flora have been obtained in relation to the feeding habits of $M$. rosenbergii, and so food preference is still uncertain in this species.

\section{Litopenaeus vannamei}

The pelagic larval history of L. vannamei includes six naupliar stages (non-feeding), three protozoeal stages, and three mysis stages. The subsequent postlarvae become benthic. Protozoea feed by filtering microalgae from the water, and the mysis and postlarvae capture zooplankton (Kumlu, 1999). The adults of Indo-Pacific penaeid shrimps exhibit similar activity patterns, typically active at night and buried inactive during the day (Hindley, 1975; Robertson et al., 1993). However, the adults of the western Atlantic penaeid shrimp including L. vannamei, are active day and night and do not bury during the day (Pérez-Farfante, 1969). For L. vannamei juveniles in captivity, swimming activity is high in the dark and feeding is high in the light (Pontes and Arruda, 2005).

Gut contents analysis showed that L. vannamei depended mainly on animal food items, and males and females of all sizes were carnivorous, with the larger specimens ingesting crustaceans, mollusks, and detritus in higher quantities than the smaller ones (Varadharajan and Pushparajan, 2013).

Ogle and Beaugez (1991) examined the food preference of adult L. vannamei in the laboratory. Nine natural food items (all frozen, minced, and thawed) and five commercial pellets were tested and presented to shrimp in separate tanks; the item consumed in the highest amount was considered the preferred food. Adult brine shrimp (Artemia salina) was the most preferred food, followed by krill (Euphausia superba), marine bloodworm (Glyceria dibranchia), oyster (Crassostrea virginica), and sandworm (Nereis virens). The squid (Lolliguncula brevis), the most commonly used food items for sexual maturation of $L$. vannamei (Ogle, 1991), was ironically not preferred in this experiment. Three fish maturation pellets were the least preferred by L. vannamei, presumably because they had been maintained on a shrimp grower pellet before the tests, and may not have liked the taste of the fish pellets. For comparison, the commonly used food for sexual maturation of Penaeus monodon is live polychaetes (Chimsung, 2014).

\section{Information from the baited trap fishery}

Baited traps are commonly employed in commercial and artisanal fisheries to capture crustaceans from the wild. Traps for Macrobrachium spp., vary widely in size, materials, and design, but many of them are baited with, or provided with lures of, indigenous plant products. Among these were the white core of the root of cassava for Macrobrachium in Liberia (Miller, 1971); boiled maize shaft for $M$. macrobrachion in Nigeria (Emmanuel and Salawu, 2009); yam stems and leaves and palm frond for M. felicinum in Nigeria (Okayi et al., 2013); coconuts and maize for Macrobrachium spp. in Puerto Rico (Alston and Carro, 2013); and palm fruit for $M$. vollenhovenii in the Amazon River (Lima et al., 2013). Coconut was also used as bait in hook and line for $M$. carcinus in Dominica (Chace and Hoobs, 1969).

Interpretation of the fisheries catch data is complicated by the fact that non-baited traps also catch Macrobrachium spp. (Emmanuel and Salawu, 2009). However, experimental fishing with baited traps provides insights into the comparative attractiveness of the baits used. Bentes et al. (2014) reported that traps baited with babassu coconut (Orbignya speciosa) lured and captured more $M$. amazonicum than those baited with catfish (Hoplosternum littorale, Callichthyidae). It seems ironic that non-protein terrestrial babasu coconut was more chemically attractive than high-protein aquatic catfish to 
M. amazonicum, but trap catch is influenced by odour plumes with different concentration gradients in turbulent water flow (Moore and Atema, 1991).

\section{Feeding behavior and sensory basis}

Feeding behaviour includes searching, detection, orientation, grasping, and ingestion of the food. Vision could be involved in the initial steps but is not considered important in crustaceans because they are generally benthic scavengers and chemoreception is more adaptive to finding fresh carrion on the sea bed where light is scarce (Premke et al., 2006). The final step in the feeding process is usually affected by taste (Harpaz, 1997). Sensory and nervous systems underlying animal behaviour have been examined well in crayfish, lobsters, and other crustaceans (Derby and Atema, 1982; Grasso and Basil, 2002; Premke et al., 2006).

\section{Macrobrachium rosenbergii}

Moller (1978) observed individual M. rosenbergii larvae and postlarvae in a watch glass under a stereo microscope to find evidence of visual ability in locating food particles. Larvae did not discriminate between different shapes and textures. Larvae made a grasping response to particles in contact, and ignored all particles not in contact ( $1 \mathrm{~mm}$ away) with the feeding appendages. Barros and Valenti (1997) reported that the food perception in distance does not occur and the feeding process started with the physical contact of food, Artemia nauplii, with the larvae in $500 \mathrm{~mL}$ beakers. In contrast, postlarvae grasped particles in contact with, and 30 $\mathrm{mm}$ away from, the feeding appendages, an indication that postlarvae used both vision and the chemical sense. Meyers and Hagood (1984) observed that M. rosenbergii larvae accepted light-coloured feed flakes better than darker flakes.

\section{Litopenaeus vannamei}

You et al. (2006) found that food intake of juvenile $L$. vannamei is significantly lower in an illuminated tank than in a dark tank, and noted that these shrimp use olfaction, not vision, in searching for food. This finding is supported by Sanudin et al. (2014) who found that postlarvae PL5 ingested more frozen Artemia nauplii under light than in the dark but that feeding of PL10-PL30 was not so affected by light.

\section{Other decapod crustaceans}

The larvae of decapod crustaceans apparently depend on chance encounters to capture food (Herrnkind, 1968). Juvenile banana shrimp (Penaeus merguiensis) detect food chemically and the chemosense is effective only over a short distance of a few centimeters (Hindley, 1975). Wang et al. (2004) found no effect of light intensities ranging from $0 \mathrm{~lx}$ to $1300 \mathrm{~lx}$ on feed intake of juvenile Chinese white shrimp (Fenneropenaeus chinensis). Harvey and Epifanio (1997) found that the preference of mud crab (Panopeus herbstii) larvae for Artemia nauplii or rotifers maintained in total dark, and concluded that prey discrimination was non-visual. Gonor and Gonor (1973) reported that larvae of four porcellanid crabs detect live Artemia nauplii by contact and not visually. In the lobster (Homarus americanus), the appendages have different functional roles in feeding behaviour; leg-ablated lobsters walked over mussels without picking them up, whereas maxilliped-ablated lobsters grasped the mussels as usual but did not crush or eat them (Derby and Atema, 1982).

\section{Vision in feeding behaviour of juveniles}

\section{Role of vision}

Vision has not been considered important in the feeding behaviour of Macrobrachium and penaeid shrimp, which are nocturnal and feed at night in the wild and in the laboratory (Fuss and Ogren, 1966; Chace and Hobbs, 1969; Hindley, 1975; Wang et al., 2004; Santos et al., 2016). However, many other studies contradict this conclusion. First, shrimp behaviour changes with size and age; Moctezuma and Blake (1981) reported that L. vannamei at $50 \mathrm{~mm}$ total length did not burrow at all, but those at $80 \mathrm{~mm}$ total length burrowed intermittently in laboratory. Second, both daytime and nightime activity has been observed among L. vannamei juveniles in the laboratory (Pontes et al., 2006), and among $M$. macrobrachion and $M$. vollenhoevenii trapped in an open lagoon (Emmanuel and Salawu, 2009). Third, conclusions about feeding behaviour depend on size of containers and other test conditions. Capture of food by larvae of $M$. rosenbergii is a matter of chance encounter in a $50 \mathrm{~mL}$ beaker (Moller, 1978), and in a $500 \mathrm{~mL}$ beaker or a $40 \mathrm{~mL}$ Petri dish (Barros and Valenti, 1997, 2003). But $M$. rosenbergii larvae in $360 \mathrm{~L}$ rearing tanks visually detect suspended food particles from a distance of $20 \mathrm{~cm}$, head straight toward them, and gather around them (Kawamura et al., 2016). Thus, penaeid shrimp and Macrobrachium spp. in fact use vision in detection of and orientation to food during daytime feeding. Of course, it is difficult to test and observe feeding behaviour in total dark.

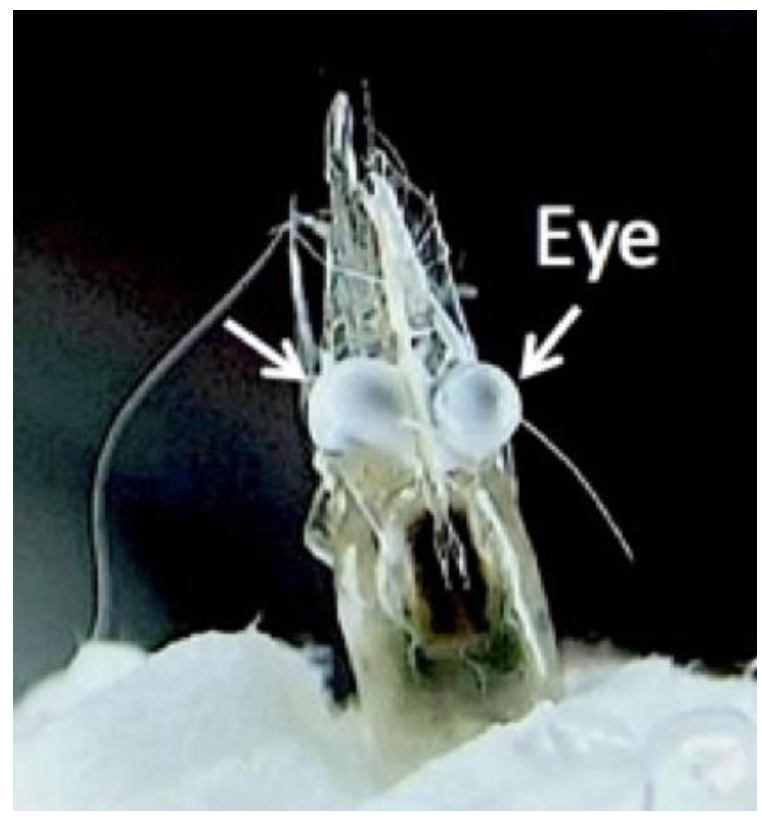

Figure 1. Macrobrachium rosenbergii juvenile with eyes blinded with white manicure 


\section{Feeding response with intact and blinded eyes}

To confirm the role of vision in feeding behaviour, an experiment was done on hatchery-produced $M$. rosenbergii juveniles (47.58-64.54 $\mathrm{mm} \mathrm{TL}$ ) and L. vannamei juveniles (40.87-69.35 mm TL) with intact eyes vs blinded eyes. The eyes were blinded by painting them over with white manicure (Figure 1). Tests were done on 10 juveniles in a transparent polystyrene aquarium $(37 \mathrm{~cm} \times 21 \mathrm{~cm} \times 28 \mathrm{~cm}$; water volume 7 L) with continuous aeration and recirculating water pumped through a biological filter under natural light in the laboratory. Movement of water (visualized with milk) was gently turbulent and not unidirectional. Dechlorinated tap water and sea water (30 ppt) was used in $M$. rosenbergii and L. vannamei tests respectively. A commercial pelleted diet (CP Aquaculture Limited, Thailand) was used in the juvenile rearing and in the feeding tests. Pellets $(1.9 \mathrm{~mm}$ in diameter, 4.7-6.2 $\mathrm{mm}$ long) were placed one at a time about $10-15 \mathrm{~cm}$ from 10 juveniles. For each postlarva, feeding behaviour in several steps was observed and recorded visually for 10 min until the pellet was ingested, i.e., the mouthparts (maxillipeds) stopped moving. Observations were repeated for nine other pellets and nine other juveniles.
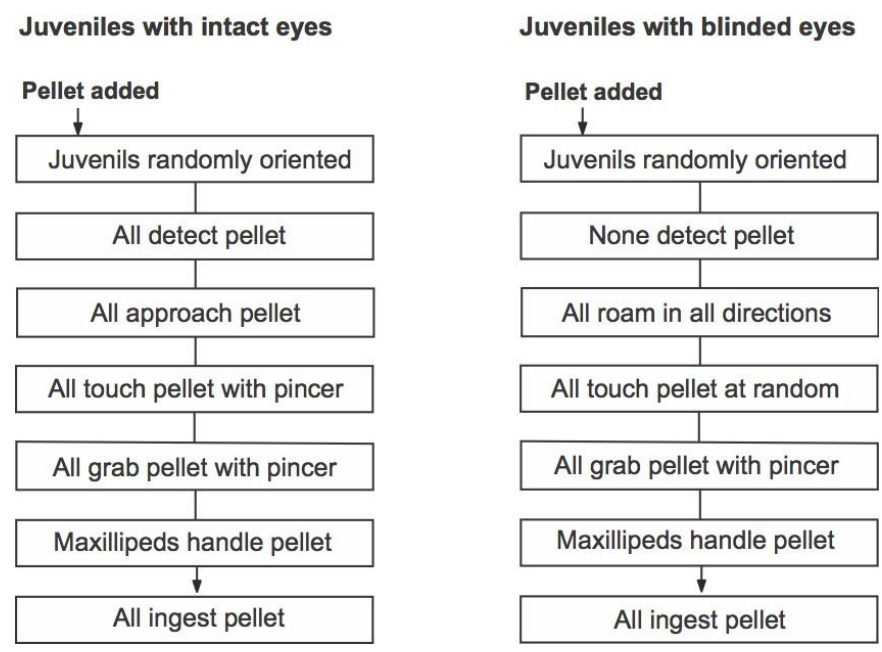

Figure 2. Macrobrachium rosenbergii. Feeding responses of juveniles with intact eyes and vs blinded eyes. Pellets were placed one at a time near 10 juveniles in an aquaria. For each pellet, feeding behaviour was observed and recorded visually for $10 \mathrm{~min}$. Observations were repeated for 10 juveniles. Handling of the pellet was indicated by movement of the maxillipeds (mouthparts). When the maxillipeds stopped, the pellet was considered ingested

\section{Macrobrachium rosenbergii}

The feeding behaviour of the juveniles of $M$. rosenbergii is shown by flowchart in Figure 2. Once a pellet was placed about $10-15 \mathrm{~cm}$ from the intact-eyed juveniles, they readily detected it, directly approached it, grabbed it, handled it with pincers, and conveyed it to the mouth within $2 \mathrm{~s}$. The juvenile often attacked and grabbed the pellet from another feeding juvenile. All 10 juveniles ingested the pellets after very short handling times. In contrast, when a pellet was placed near the blinded juveniles, they continued to roam the tank bottom at random, detected the pellets only by random touch with the walking legs, but eventually all grabbed and ingested the pellets within 10 min (Figure 2). During roaming, the antennae were usually pointed backward or dorso-laterally; a pellet that touched the antenna did not elicit the feeding response in either the intact or the blinded juveniles.

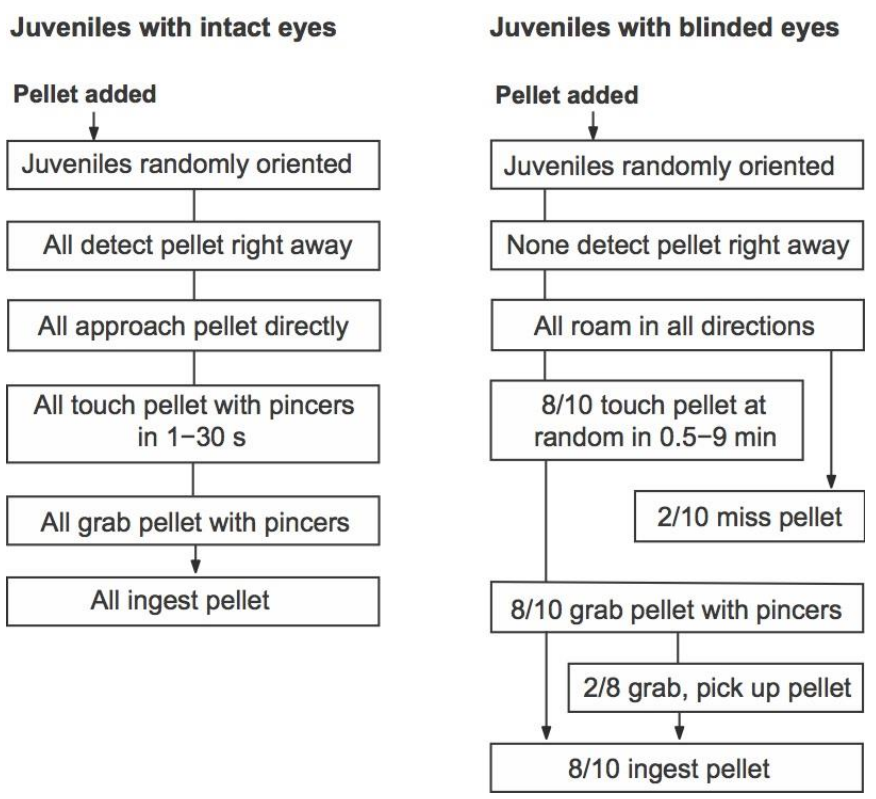

Figure 3. Litopenaeus vannamei. Feeding responses of juveniles with intact eyes and vs blinded eyes. Pellets were placed one at a time near 10 juveniles in an aquarium. For each pellet, feeding behaviour was observed and recorded visually for $10 \mathrm{~min}$. Observations were repeated for 10 juveniles. Movement of the maxillipeds was not seen, but the pellets were ingested

\section{Litopenaeus vannamei}

It seemed that $L$. vannamei juveniles (reared on pellets for one week prior to the tests) depended on vision more than $M$. rosenbergii and were disabled to a greater extent by temporary blinding. All intact-eyed juveniles quickly detected, approached, grabbed with pincers, and ingested the pellets (Figure 3). The blinded juveniles did not detect the pellets until they randomly touched them after 0.5-9 min. Two juveniles missed the pellets completely, but eight managed to grab and ingest the pellets within $10 \mathrm{~min}$. During roaming, the antennae were usually pointed backward or dorso-laterally; the juveniles did not respond to a pellet touched with the antennae.

\section{Visual response to pellet-like pebbles}

Feed pellets convey visual and chemical stimuli to juveniles. To isolate the visual stimulus and exclude the chemical stimulus, feed pellets were replaced with pebbles of similar size, texture, and colour (Figure 4). In preliminary tests, $M$. rosenbergii juveniles did not respond to a white or grey pebble at all, an indication that the juveniles had learned the colour of the pellets during rearing in the hatchery. Tests 
were then done on the feeding response of juveniles of $M$. rosenbergii and $L$. vannamei to pellets and pellet-like pebbles placed alternately one at a time at random at the aquarium bottom.

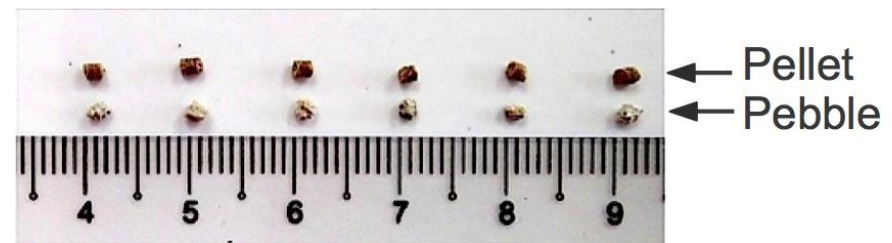

Figure 4. Pebbles used to replace pellets as visual stimulus without smell or taste. Ruler shows $1 \mathrm{~mm}$ intervals

\section{Macrobrachium rosenbergii}

Intact-eyed juveniles of $M$. rosenbergii detected a pebble right away, approached it directly, touched and grabbed it with the pincers, and finally discarded it after much handling (Figure 5). The earlier responses were visual and similar to the response to pellets, but the final response was not to ingest but rather to discard the pebble. The handling of the pebble with the pincers elicited information on texture through the tactile sense.

Tests done on blinded juveniles showed that they roamed the bottom in all directions and detected a pebble only upon random touch with the pincer; the pebble was manipulated with a pair of pincers but finally discarded (data not shown). This blind response to a pebble indicates the involvement of the tactile sense in feeding.

Juveniles with intact eyes
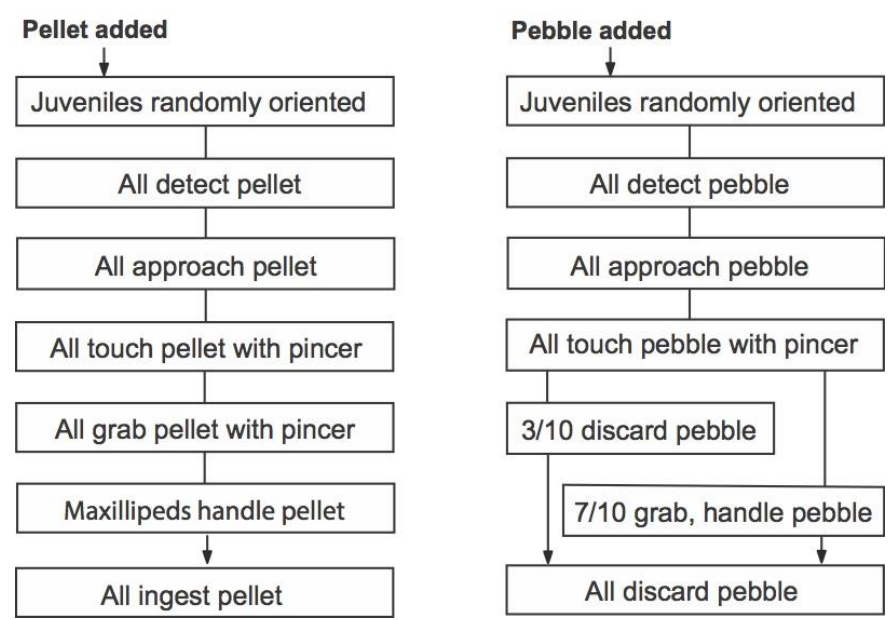

Figure 5. Macrobrachium rosenbergii. Feeding response of juveniles to feed pellets and pellet-like pebbles presented alternately. A juvenile detected and approached a pebble directly, handled it like a pellet, but finally discarded it

\section{Litopenaeus vannamei}

The juveniles of L. vannamei that had been reared with formulated feed in powder form and were naïve with the pellets used in the feeding tests mostly (8/10) did not respond to a pellet-like pebble (Figure 6). The juveniles that had been fed pellets for $3 \mathrm{~d}$ visually recognized a pebble as a pellet, handled it for some time, but finally discarded it. This result showed that the visual feeding response to a pebble was a learned behaviour. Here is the first evidence and first report of learning of visual cues by shrimp juveniles. In contrast, learning of chemical cues of food and the plasticity of feeding behaviour in decapod crustaceans have been reported by many authors (reviewed in Derby et al., 2001).
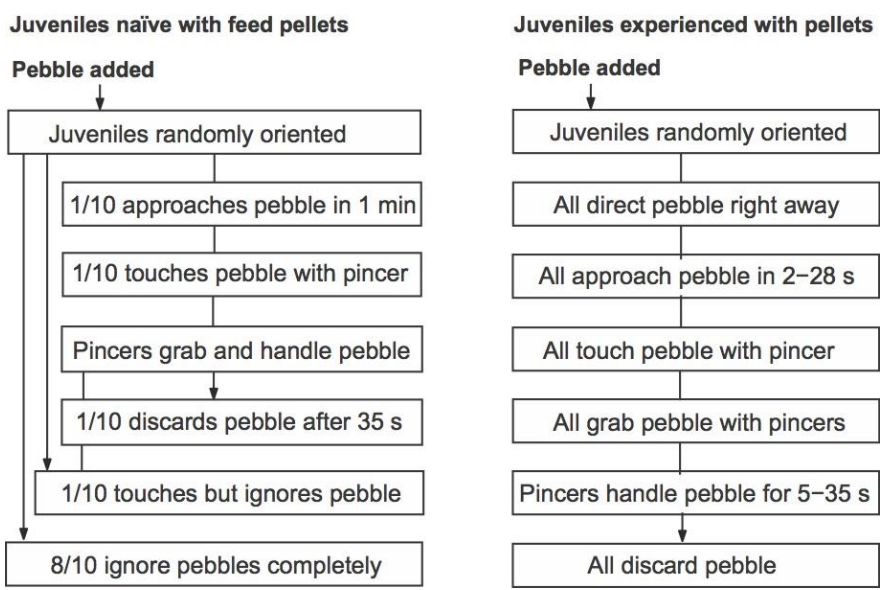

Figure 6. Litopenaeus vannamei. Feeding response of intacteyed juveniles that were either naïve or experienced with pellets. Whereas most naïve juveniles ignored a pebble, those that had fed on pellets for $3 \mathrm{~d}$ visually recognized a pebble as a pellet, grabbed and handled it for some time, but finally discarded it

\section{Colour vision and food colour preference}

Each food item is characterized by size, shape, colour, brightness and motion. Although most prey are inconspicuously coloured, the colour may still be an important factor in the prey choice of predators (Johnsen et al., 2002). Food colour preference indicates recognition of food items and has practical application in the making of visual baits.

The colours of the farm environment have significant effects on growth and the stress response of aquaculture species (Kawamura et al., 2015). The colours of background and incident light, tank walls, and shelters affect feeding, growth and stress response of farmed crustaceans (Wurts and Stickney, 1984; Wang et al., 2003; Yasharian et al., 2005; Tidwell and Coyle, 2008; Luchiari et al., 2012). Experiments on the effect of colour have been based on the assumption that the test animals have colour vision. Colour vision has been speculated in the Crustacea based on the types of photoreceptors in the eyes (Marshall et al., 1996; Kashiyama et al., 2009; Rajkumar et al., 2010). Colour vision requires at least two types of spectral receptors (Kelber and Osorio, 2010), but most decapod crustaceans are reported to have only a single type of photoreceptor (Johnson et al., 2002). 
Most knowledge of the visual system necessarily comes from physiological and opsin transcript studies, but only behavioural (psychophysical) studies can tell what the animal's visual system is truly capable of achieving (Douglas and Hawryshyn, 1990). Stomatopods and M. rosenbergii are currently the only crustaceans known to possess true, behaviourally demonstrated colour vision (Marshall et al., 1996; Theon et al., 2014; Kawamura et al., 2016).

Preference tests have been widely used to determine the best environmental conditions for captive animals. To make a choice, the test animals must be able to discriminate between pleasant and unpleasant conditions, and choose the ones that best fit their comfort zones. Earlier colour preference tests for penaeid shrimp implied colour vision (Wurts and Stickney, 1984; Wang et al., 2003; Guo et al., 2011; Luchiari et al., 2012). A colour preference test can show that an animal can distinguish colours, but does not prove that it has colour vision, for these are not always the same (von Frisch, 1950).

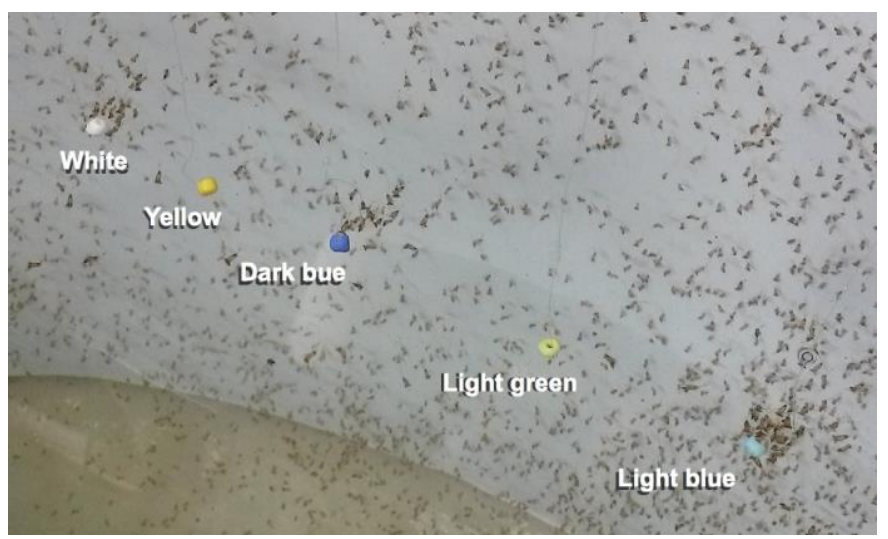

Figure 7. Macrobrachium rosenbergii. Photographs showing the aggregation of larvae (zoeae) around white and blue plastic beads suspended in a rearing tank

\section{Macrobrachium rosenbergii larvae}

Kawamura et al. (2016) examined for the first time the colour preference and possible colour vision of the larvae (zoeae) of $M$. rosenbergii by means of an experiment that took advantage of the natural swimming behaviour, and particularly the attraction to, and congregation around, large suspended particles in a rearing tank. Zoeae usually swim backward with the body dorsal side of the body facing down, but they approach suspended food particles and plastic beads head first and body dorsal side up.

When combinations of several colour beads including different shades of grey were displayed, the larvae swam straight to the beads of specific colours from all directions from distances as far as $20 \mathrm{~cm}$. The larvae oriented head first and gathered around the beads (Figure 7); some of them touched a bead several times and then swam away. The larvae exhibited significantly biased attraction to blue and white, and this colour preference is innate. They discriminated blue based mainly on colour (chromaticity) and thus have true colour vision (Kawamura et al., 2016). This colour vision seen among the zoeae presumably persists through ontogeny of $M$. rosenbergii given that the metamorphic change in visual pigments does not occur in decapod crustaceans (Cronin et al., 1995).

Given the above result with blue being an attractive colour for zoeae, a larval rearing experiment was conducted using blue-dyed versus normal-yellow egg custard as feed (Yong et al., in preparation). After $30 \mathrm{~d}$ rearing, larvae reared with blue custard were significantly larger in mean body weight and total length than those reared with yellow custard (Figure 8). The zoeae in the blue-custard group also had fewer days to metamorphosis into postlarvae, but not significantly different from the yellow-custard group. Still it is evident that feeding is promoted by food with the preferred colour.

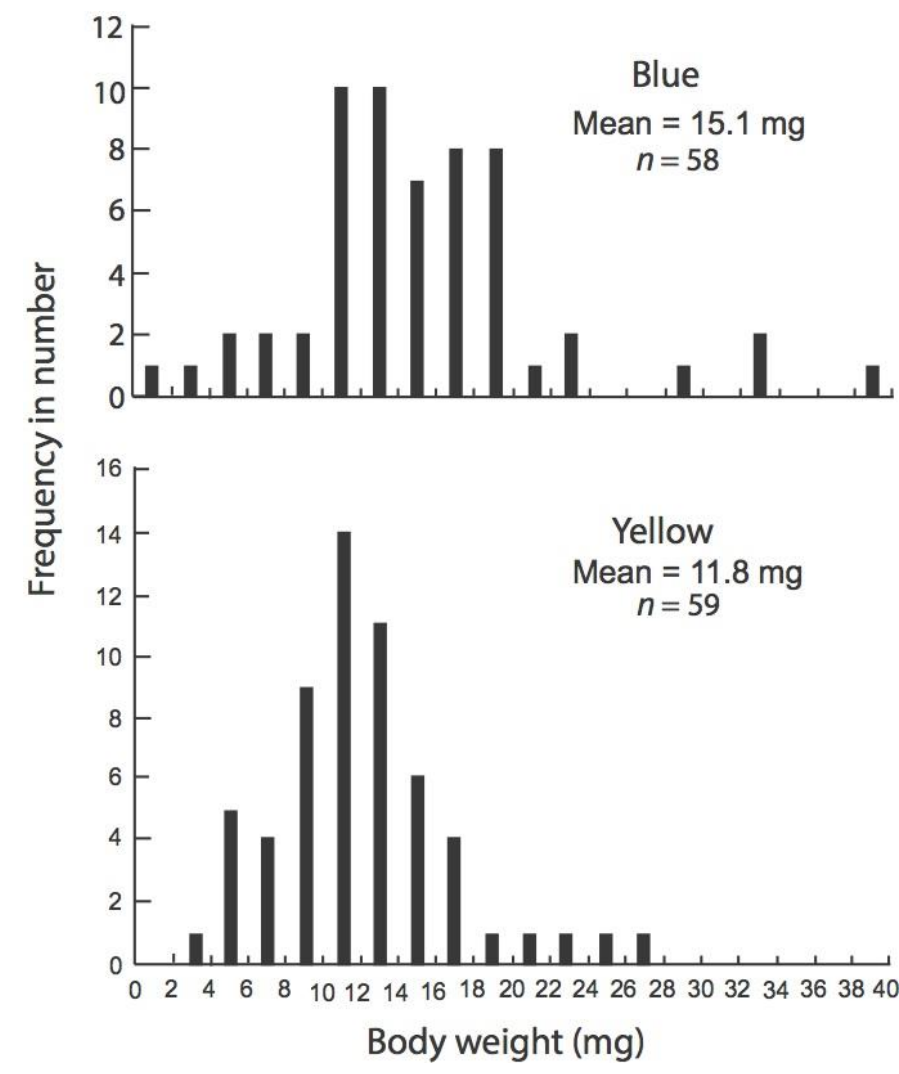

Figure 8. Macrobrachium rosenbergii. Frequency distribution of body weight of larvae after 30 $\mathrm{d}$ rearing. The mean body weight is significantly higher among larvae reared with blue-dyed egg custard than those reared with normal yellow egg custard (WilcoxonMann-Whitney test, $z=-3.464, P=0.00054$ )

\section{Litopenaeus vannamei adults}

Colour of light in hatchery tanks affects growth, ovarian maturation, and spawning of Penaeus plebejus, $P$. indicus, and P. monodon (Kelemec and Smith, 1980; Pudadera and Primavera, 1981; Emmerson et al., 1983; Primavera and Caballero, 1992). These results indicate that penaeid shrimp are capable of colour perception, but colour vision has not been examined for this group. 


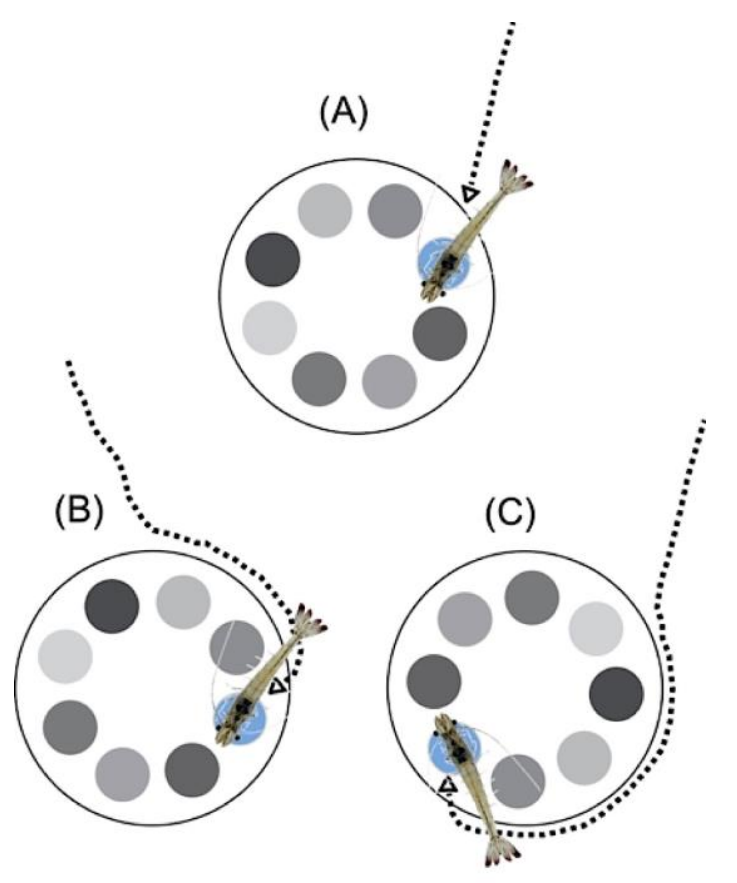

Figure 9. Litopenaeus vannamei. White palettes with a bluepainted well among seven wells painted different shades of gray. The blue well contained feed pellets as reward during the conditioning trials and no pellets during the color vision tests. Illustration shows the conditioned response of adults during the non-rewarded test trials: the shrimp stopped at the blue well for 1-8 $\mathrm{s}$ regardless of the position of the blue well among the grey wells. Dotted lines show typical trajectories-the shrimps rarely walked on the grey wells

Classical conditioning and behavioural tests were used to determine colour vision and food colour preference in adult $L$. vannamei. In the roofed hatchery of the Borneo Marine Research Institute, 6 adults were placed in 6 transparent polystyrene aquaria $(37 \mathrm{~cm} \times 21 \mathrm{~cm} \times 28 \mathrm{~cm}$ height) filled to a water depth of $20 \mathrm{~cm}$, equipped with an airlift biofiltration unit under natural light. The adults were trained individually to feed from a white palette $15 \mathrm{~cm}$ diameter) with a blue-painted well-arranged among 7 wells painted different shades of grey (Figure 9). The light reflectance spectra of the blue paint and the 7 grey shades are shown in Figure 10. The blue paint had a peak reflectance at $500 \mathrm{~nm}$ to match the peak spectral sensitivity of the visual pigment of L. vannamei at $500 \mathrm{~nm}$ (Matsuda et al., 2011).

During conditioning with a food reward, a single feed pellet was placed in the blue well; the shrimp approached the palette in an erratic way, probed the bottom with the first three pairs of legs, walked on the rim of the palette, and tentatively approached the blue well. After 130 rewarded training trials in $34 \mathrm{~d}$, the six adults were tested to see if they had learned the training task, i.e., the association of the feed reward with the blue well. Non-rewarded test trials were conducted where the palette with no feed in the blue well was displayed to each shrimp 5 times a day. When the empty palette was placed on the aquarium bottom, each of the six conditioned shrimps approached it, exhibited food search behavior, walked on it, and stopped at the blue well for 1-8 s (Figure 9). The shrimp never stopped at any of the grey wells. This behaviour indicated that all six adult shrimp had learned the conditioning task, discriminated blue from grey shades by hue rather than brightness, and therefore had colour vision.

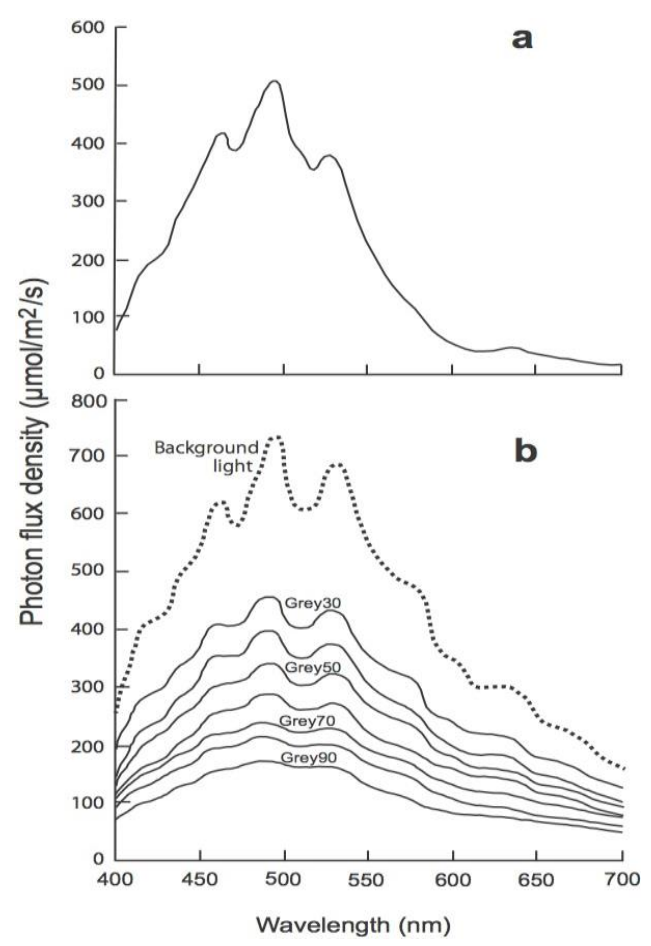

Figure 10. Light reflectance spectra for (a) blue paint and (b) seven shades of grey and the background light measured with a spectroradiometer (HSR-8100, Maki Manufacturing Co., Ltd., Hamamatsu, Japan)

Colour vision and food colour preference, innate or learned, have been well documented among insects (Briscoe and Chittka, 2001; Miller et al., 2011). However, food colour preference has not been studied in crustaceans probably because the omnivorous feeding habits present considerable difficulty in experimental design. Tiews et al. (1968) examined the gut contents of Penaeus semisulcatus, $P$. merguiensis and $P$. canaliculatus and found selective feeding among available prey. Selective feeding by vision may also be expected in L. vannamei given that they are active day and night and the young do not burrow during daytime (PérezFarfante, 1969).

A behavioural experiment was conducted to determine the food colour preference of each of the six adult L. vannamei under daylight in an aquarium $(37 \mathrm{~cm} \times 21 \mathrm{~cm} \times$ $28 \mathrm{~cm}$ height, filled to a depth of $20 \mathrm{~cm}$ ) equipped with an airlift biofiltration unit. The adults were fed the flesh of the marine western king prawn (Melicertus latisulcatus, identified by Dr. Hideo Sakaji, National Research Institute of Fisheries and Environment of Inland Sea, Japan) dyed in five colours: yellow, red, green, blue (with food dyes) and black 
(with Chinese ink). The reflectance spectra of natural western king prawn flesh and the five dyed prawn flesh are shown in Figure 11. The yellow-dyed prawn flesh was most similar to the natural prawn flesh in terms of spectrum (albeit with blue wavelengths cut off) and brightness. The different coloured prawn flesh were presented in colour pairs at the aquarium bottom with brown background. The first colour to be grabbed by L. vannamei was considered the preferred food colour, according to the method of Kawamura et al. (2010). Quantitative analysis of the frequency of first grab, as the z-score, was done by means of the Thurstone's law of comparative judgment (Thurstone, 1927).

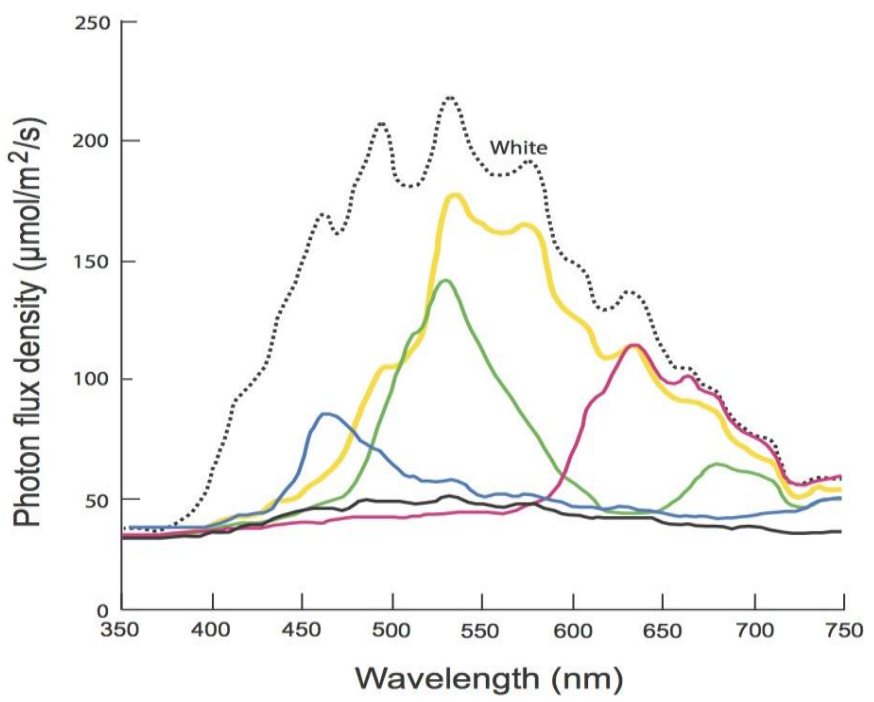

Figure 11. Reflectance spectra of natural prawn flesh and those coloured yellow, red, green, blue (with food dyes) and black (with Chinese ink)

Adult L. vannamei grabbed all coloured prawn flesh without hesitation, which meant that the dyes did not affect the attractiveness of the prawn flesh. The mean z-score of the first-grab colours was significantly highest for yellowdyed prawn flesh and not significantly different among the four other prawn flesh colours in tests done against a brown aquarium bottom (Figure 12). A subsequent experiment showed the same yellow food preference against a black aquarium bottom (Table 1). Another experiment even showed a yellow food preference (37 first grabs) over natural prawn flesh (16 first grabs) $\left(\chi^{2}=8.32, P<0.005\right)$ against a black aquarium bottom. The distinct preference of L. vannamei for yellow food seems innate since it could not be explained by associative learning-these farmed shrimp had never experienced yellow food during rearing in the hatchery.

Table 1. Litopenaeus vannamei. Frequencies of first grabs of coloured shrimp flesh presented as colour pairs against a black aquarium bottom.

Frequencies of first grabs by colour pair (left colour: top colour)

\begin{tabular}{ccccc}
\cline { 2 - 4 } & Black & Green & Blue & Red \\
\hline Yellow & $21: 4^{* * *}$ & $18: 7^{* *}$ & $19: 7^{* *}$ & $22: 9^{*}$ \\
\hline Asterisks *, & (*) and $^{* * *}$ indicate significance at $\alpha=0.05,0.01$ and 0.005 respectively
\end{tabular}
$\left(\chi^{2}\right.$ test)

\section{Chemoreception in juveniles}

Olfaction disrupted by ablation of antennular flagella

In crustaceans, including $M$. rosenbergii, olfaction is mediated by the aesthetascs and non-aesthetascs sensilla of the antennules (Hallberg et al., 1992; Horner, 2007). Olfaction is involved in three different behaviours; orientation to a distant food odor, shelter selection in response to conspecific chemical signals, and determination of conspecific social status (Horner, 2007). Using mainly lobsters and crayfish as model organisms, many behavioural studies have been done involving selective ablation of specific populations of antennular sensilla (Horner, 2007). We examined the effect of olfactory ablation on feeding of the juveniles of $M$. rosenbergii and L. vannamei. An electric cauterizer was used to ablate a pair of flagella in both antennules of 10 juveniles. Then the odour-tracking behaviour of the ablated juveniles in a Y-maze flume tank was compared with that of 10 intact non-ablated juveniles. All intact juveniles of both species responded to $20 \mathrm{~mL}$ extract of feed (passed through Whatman filter paper No. 1) from the stimulus arm of the flume tank, whereas all ablated juveniles did not respond and stayed in the drain arm for 30 min. This result showed that olfaction of juveniles was mediated by the flagella in the antennules.

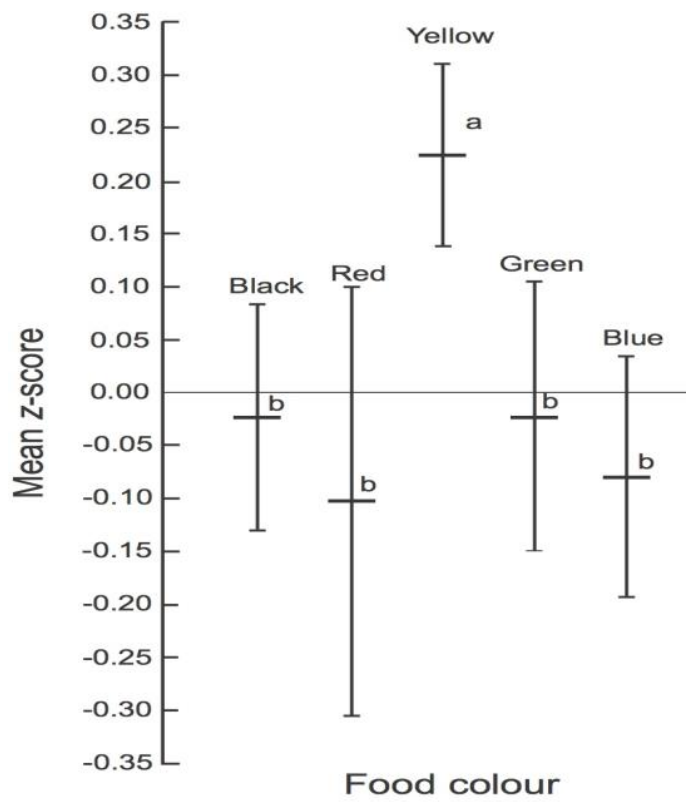

Figure 12. Litopenaeus vannamei. Mean z-scores for the first-grab response of adults to prawn flesh dyed different colours and presented in colour pairs (each pair 50-70 times) at the bottom of an aquarium with brown background. Vertical bars, $95 \%$ confidence interval, Thurstone's law of comparative judgment

\section{Chemoreception disrupted by osmotic ablation}

Exposure to distilled water functionally ablates chemosensory neurons in marine crustaceans by osmotically disrupting the outer dendritic segments of the chemosensory neurons located in the permeable chemosensilla, while retaining the function of at least some of the 
mechanosensory neurons (Derby and Atema, 1982; Gleeson et al., 1996; Steullet et al., 2001). Osmotic ablation of the Caribbean spiny lobster (Panulirus argus) was done by placing the flagella of the antennules in distilled water for 15-30 min (Steullet et al., 2001).

Osmotic ablation was carried out on four groups of 10 juveniles of $M$. rosenbergii by transferring them from fresh water $(0 \mathrm{ppt})$ directly to sea water $(30 \mathrm{ppt})$ for exposure periods of $0.5 \mathrm{~h}, 1 \mathrm{~h}, 2 \mathrm{~h}$, and $3 \mathrm{~h}$. There was no mortality from these treatments. Osmotic ablation was also carried out on three groups of 10 juveniles of L. vannamei by directly transferring them from sea water of $30 \mathrm{ppt}$ salinity to distilled water ( $0 \mathrm{ppt}$ ) for exposure periods of $0.5 \mathrm{~h}, 1 \mathrm{~h}$, and $2 \mathrm{~h}$. The first two treatments caused no deaths, but the $2 \mathrm{~h}$ exposure resulted in $80 \%$ mortality. All the juveniles had been fed pellets before the osmotic ablation. The different groups of ablated juveniles were kept in separate test aquaria for a day before the tests to evaluate the effect of osmotic ablation on feeding by chemoreception. Using the same protocols described earlier, a single pellet was presented to a group of intact or ablated juveniles in an aquarium and the feeding response was visually recorded for $15 \mathrm{~min}$.

\section{Macrobrachium rosenbergii}

The feeding response of non-ablated juveniles was the same as that of the intact juveniles in Figure 2, where the pellet was detected, approached, grabbed, handled, and ingested within seconds. Feeding response was not affected by osmotic ablation from seawater exposure for $0.5-1 \mathrm{~h}$. In the $2 \mathrm{~h}$ treatment, the ablated juveniles approached and grabbed 8 of 10 pellets, discarded one, and ingested seven (data not shown). The effect of the $3 \mathrm{~h}$ seawater treatment on the feeding response was most striking - only one pellet was ingested and nine pellets were discarded, four of these after handling with the pincers and maxillipeds for as long as 2 min (Figure 13). These results indicated that the osmotically ablated juveniles were capable of pellet detection by vision, handling was elicited by the physical character of the pellet, and chemoreception determined ingestion.

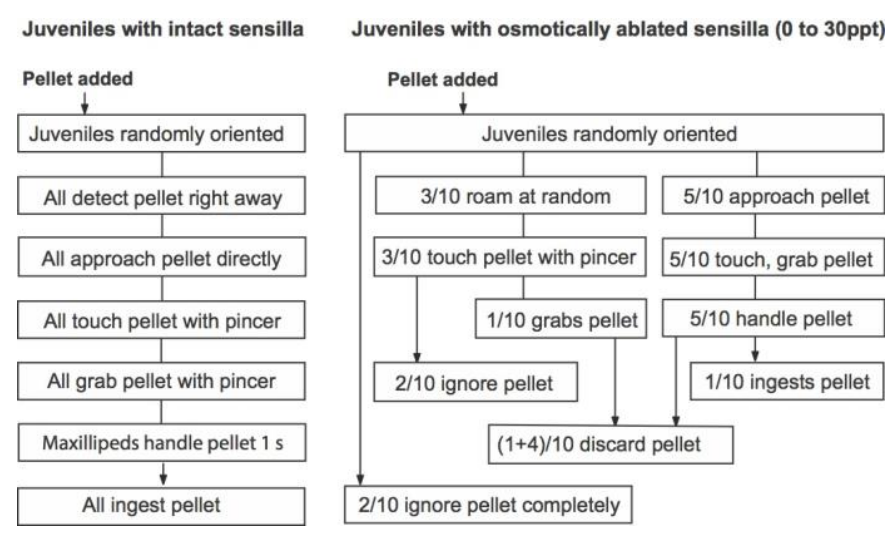

Figure 13. Macrobrachium rosenbergii. Feeding response of intact and osmotically ablated juveniles transferred from fresh water ( $0 \mathrm{ppt}$ ) and kept in $30 \mathrm{ppt}$ sea water for $3 \mathrm{~h}$

\section{Litopenaeus vannamei}

Feeding response to a feed pellet was not affected by osmotic ablation from distilled water exposure for $30 \mathrm{~min}$ (data not shown). All intact juveniles approached a pellet directly, grabbed and handled it with the pincer and maxillipeds, and ingested it (as shown in Figure 3). Among those treated for 1 $h$, two discarded their pellets after handling with the pincers, but two others grabbed and ingested it (Figure 14). The two juveniles that survived the $2 \mathrm{~h}$ treatment ingested pellets in the same manner as the non-ablated ones. Given that osmotic ablation destroyed the chemosensitive sensilla, it is likely that the juveniles learned the visual cue and texture of the pellets and recognized them by vision and tactile sense.

\begin{tabular}{|c|c|}
\hline Juveniles with intact sensilla & Juveniles with ablated sensilla \\
\hline Pellet added & Pellet added \\
\hline Juveniles randomly oriented & Juveniles randomly oriented \\
\hline All detect pellet right away & All detect pellet right away \\
\hline All approach nellet directlv & All annroach nellet directlly \\
\hline All t tuch nellet with nincer & All touch pellet with pincer \\
\hline & \\
\hline All grab pellet with pincers & All grab pellet with pincers \\
\hline & \\
\hline Pincers handle pellet $1-2 \mathrm{~s}$ & Pincers handle pellet $2-5 \mathrm{~s}$ \\
\hline$\downarrow$ & $\downarrow$ \\
\hline All ingest pellet & $8 / 10$ ingest pellet right away \\
\hline & 2/10 discard pellet \\
\hline & $2 / 10$ others grab, ingest pellet \\
\hline
\end{tabular}

Figure 14. Litopenaeus vannamei. Feeding response of intact and osmotically ablated juveniles transferred from 30 ppt sea water and kept in distilled water $(0$ ppt) for $1 \mathrm{~h}$

\section{Sensory appendages in Litopenaeus vannamei juveniles}

Aquatic crustaceans bear chemoreceptive and mechanoreceptive cuticular sensilla on the body, including the abdomen (Felgenhauer and Abele, 1983; Hellon, 2007; Schmidt and Mellon, 2011). The head of decapod shrimp has many appendages including a pair of long antennal flagella, a pair of antennules with short flagella, three pairs of maxillipeds (mouthparts), and five pairs of pereiopods. In penaeids such as L. vannamei, the first three pairs of pereiopods bear small pincers used for feeding, and other two pairs are used for walking. In palaemonids such as $M$. rosenbergii, the first two pairs of pereiopods bear pincers and other three pairs do not.

To determine the role of sensory appendages in feeding of L. vannamei juveniles, we cauterized the antennal flagella, antennular flagella, the pincers of the pereipods, but not the maxillipeds (Figure 15). This ablation did not cause mortality. A group of 10 ablated juveniles was allowed to recover for $24 \mathrm{~h}$ while kept in an aquarium and then tested 
for feeding response by means of the same protocol described earlier.
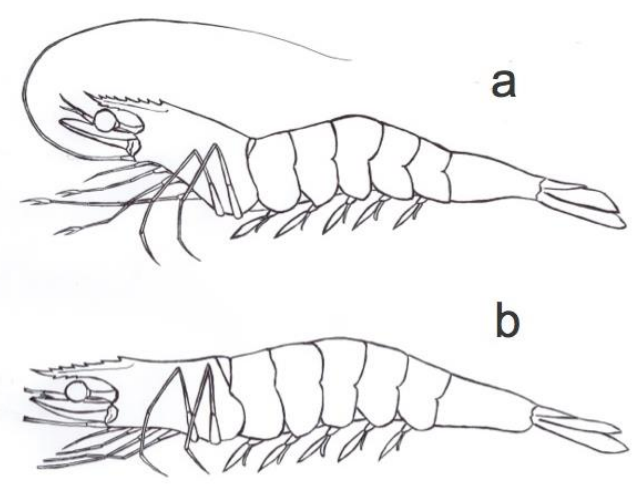

Figure 15. Litopenaeus vannamei. (a) Intact juveniles in usual food search posture; (b) Ablated juveniles (with antennae, flagella of antennules, and pincers of the walking legs cauterized) in modified food search posture where the head is lowered to bring the maxillipeds closer to the bottom to detect, grab, and handle food. Drawing by Au Hsein Loong

The ablated juveniles were sluggish and dispersed at the aquarium bottom. They did not react to random contact with the others. They opened and flicked the maxillipeds. They did not approach a pellet, even one placed close by, probably because they did not visually recognize a pellet as food since they had been reared with formulated diet in powder form. Although the juveniles did not respond to a pellet encountered during roaming, they seized a pellet that came near the maxillipeds from currents generated by the swimming legs. Such pellets were grabbed by the maxillipeds and then ingested. After the juveniles experienced such random pellet contact and grab with the maxillipeds, and the resulting satiation, they seemed to change the food search behaviour-they lowered the head, actively swam forward, swept the bottom with the maxillipeds, detected a pellet, grabbed it, and ingested it (Figure 15). These results indicate a plasticity in feeding behaviour in L. vannamei. Similar modification of feeding behaviour after loss of chelipeds is well known in crabs-the crab lowers the body and uses the maxillipeds as the food detection and handling tool (Oliveira et al., 2015).

\section{References}

Alston, D.E. \& Carro, A. (2013). Techniques used for catching freshwater shrimp in Puerto Rico. Proceedings of the Thirty-Ninth Annual Gulf and Caribbean Fisheries Institute, Charleston, South Carolina 39, 240-243.

Barros, H.P. \& Valenti, W.C. (1997). Feeding behavior of the prawn, Macrobrachium rosenbergii (De Man) (Crustacea, Palaemonidae), during the larval phase: qualitative analysis. Revista Brasileira de Zoologia 14, 785-793.

Barros, H.P. \& Valenti, W.C. (2003). Ingestion rates of Artemia nauplii for different larval stages of Macrobrachium rosenbergii. Aquaculture 217, 223-233.

Bentes, B., Martinelli-Lemos, J.M., Paes, E.T. et al. (2014). Experimental study on the efficiency of different types of traps and baits for harvesting Macrobrachium amazonicum (Heller, 1862). Maringá 36, 383-391.
Briscoe, A.D. \& Chittka, L. (2001). The evolution of color vision in insects. Annual Review of Entomology 46, 471-510.

Chace, F.A., Jr. \& Hobbs, H.H., Jr. (1969). The freshwater and terrestrial decapod crustaceans of the West Indies with special reference to Dominica. United States National Museum Bulletin No. 292. Smithsonian Institution Press, Washington, D.C., USA

Chimsung, N. (2014). Maturation diets for black tiger shrimp (Penaeus monodon) broodstock: a review. Songklanakarin Journal of Science and Technology 36, 267-273.

Costa, H.H. \& Wanninayake, T.B. (1986). Food, feeding of the giant freshwater prawn Macrobrachium rosenbergii from natural habitat in Sri Lanka. In: The First Asian Fisheries Forum (J.L. Maclean, L.B. Dizon \& L.V. Hostillos, eds.), pp 555-558. Asian Fisheries Society, Manila, Philippines

Cronin, T.W., Marshall, N.J., Caldwell, R.L. et al. (1995). Compound eyes and ocular pigments of crustacean larvae (Stomatopoda and Decapoda, Brachyura). Marine and Freshwater Behaviour and Physiology 26, 219231.

Derby, C.D. \& Atema, J. (1982). The function of chemo- and mechanoreception in lobster (Homarus americanus) feeding behaviour. Journal of Experimental Biology 98, 317-327.

Derby, C.D., Steullet, P., Horner, A.J. et al. (2001). The sensory basis of feeding behaviour in the Caribbean spiny lobster Panulirus argus. Marine and Freshwater Research 52, 1339-1350.

Douglas, R.H. \& Hawryshyn, C.W. (1990). Behavioral studies of fish vision: An analysis of visual capabilities. In: The Visual System of Fish (R.G. Douglas \& M.B.A. Djamgoz, eds.), pp 373-418. Chapman and Hall, London, UK

Emmanuel, B.E. \& Salawu, A.T. (2009). Techno-economics of lined single basket trap fishery and environmental conditions in a tropical open lagoon in South-Western Nigeria. Research Journal of Fisheries and Hydrobiology 4, 46-54.

Emmerson, W. D., Hayes, D.P. \& Ngonyame, M. (1983). Growth and maturation of Penaeus indicus under blue and green light. South African Journal of Zoology 18, 71-75.

Fuss, C.M., Jr., \& Ogren, L.H. (1966). Factors affecting activity and burrowing habits of the pink shrimp, Penaeus duorarum Burkenroad. Biological Bulletin 130, 170-191.

Gleeson, R.A., McDowell, L.M. \& Aldrich, H.C. (1996). Structure of the aesthetasc (olfactory) sensilla of the blue crab, Callinectes sapidus: transformations as a function of salinity. Cell Tissue Research 284, 279 288.

Gonor, S.L. \& Gonor, J.J. (1973). Feeding, cleaning, and swimming behavior in larval stages of porcellanid crabs (Crustacea: Anomura). Fishery Bulletin 71, 225-234.

Grasso, F.W. \& Basil, J.A. (2002). How lobsters, crayfish, and crab locate sources of odor: current perspectives and future directions. Current Opinion Neurobiology 12, 721-727.

Guo, B., Wang, F., Dong, S. et al. (2011). Effect of rhythmic light color fluctuation on the molting and growth of Litopenaeus vannamei. Aquaculture 314, 210-214.

Felgenhauer, B.E. \& Abele, L.G. (1983). Ultrastructure and functional morphology of feeding and associated appendages in the tropical freshwater shrimp Atya innocuous (Herbst) with notes on its ecology. Journal of Crustacean Biology 3, 336-363.

Hallberg, E., Johansson, K.U. \& Elofsson, R. (1992). The aesthetasc concept: structural variations of putative olfactory receptor cell complexes in Crustacea. Microscopy Research and Technique 22, 325-335.

Harpaz, S. (1997). Enhancement of growth in juvenile freshwater prawns, Macrobrachium rosenbergii, through the use of a chemoattractant. Aquaculture 156, 221-227. 
Harvey, E.A. \& Epifanio, C.E. (1997). Prey selection by larvae of the common mud crab Panopeus herbstii Milne-Edwards. Journal of Experimental Marine Biology and Ecology 217, 79-91.

Hellon, D.F. Jr. (2007). Combining dissimilar senses: central processing of hydrodynamic and chemosensory inputs in aquatic crustaceans. Biological Bulletin 213, 1-11.

Herrnkind, W.E. (1968). The breeding of Uca pugilator (Bosc) and mass rearing of the larvae with comments on the behavior of the larval and early crab stages (Brachyura, Ocypodidae). Crustaceana Supplement No. 2, 214224.

Hindley, J.P.R. (1975). Effects of endogenous and some exogenous factors on the activity of the juvenile banana prawn Penaeus merguiensis. Marine Biology 29, 1-18.

Horner, A.J. (2007). Functional roles of crustacean dual antennular chemosensory pathways in odor mediated behaviors. Dissertation, Georgia State University.

Johnsen, S. (2002). Cryptic and conspicuous coloration in the pelagic environment. Proceedings of the Royal Society of London B 269(1488), 243-256.

Johnson, M.L., Gaten, E. \& Shelton, P.M.J. (2002) Spectral sensitivities of five marine decapod crustaceans and a review of spectral sensitivity variation in relation to habitat. Journal of the Marine Biological Association UK 82, 835-842.

Kashiyama, K., Seki, T., Numata, M. et al. (2009) Molecular characterization of visual pigments in Branchiopoda and the evolution of opsins in Arthropoda. Molecular Biology and Evolution 26, 299-311.

Kawamura, G., Kasedou, T., Tamiya, T. et al. (2010). Colour preference of five marine fishes: bias for natural and yellow-dyed krill in laboratory tanks, sea cages and earthen pond. Marine and Freshwater Behaviour and Physiology 43, 169-182.

Kawamura, G., Bagarinao, T.U. \& Lim, L.S. (2015). Fish behaviour and aquaculture. In: Aquaculture Ecosystems: Adaptability and Sustainability (S. Mustafa \& R. Shapawi, eds.), pp 68-106. Wiley-Blackwell, Oxford, UK

Kawamura, G., Bagarinao, T., Yong, A.S.K. et al. (2016). Colour preference and colour vision of the larvae of the giant freshwater prawn Macrobrachium rosenbergii. Journal of Experimental Marine Biology and Ecology 474, 67-72.

Kelber, A. \& Osorio, D. (2010). From spectral information to animal colour vision: experiments and concepts. Proceedings of the Royal Society B 277, 1617-1625.

Kelemec, J.A. \& Smith, I.R. (1980). Induced ovarian development and spawning of Penaeus plebejus in a recirculating laboratory tank after unilateral eyestalk enucleation. Aquaculture 21, 55-62.

Kumlu, M. (1999). Feeding and digestion in larval decapod crustaceans. Turkish Journal of Biology 23, 215-229.

Lee, P.G., Blake, N.J. \& Rodrick, G.E. (1980). A quantitative analysis of digestive enzymes for the freshwater prawn Macrobrachium rosenbergii. Journal of the World Aquaculture Society 11, 392-402.

Lima, J.F., Silva, T.C., Silva, L.M.A. et al. (2013). Brachyuran crustaceans from the bycatch of prawn fisheries at the mouth of the Amazon river. Acta Amazonica 43, 91-98.

Luchiari, A.C., Maroques, A.O. \& Freire, F.A.M. (2012). Effect of substrate colour preference on growth of the shrimp Litopenaeeus vannamei (Boone, 1931) (Decapoda, Penaeoidae). Curstaceana 85, 789-800.

Marshall, N.J., Jones, J.P. \& Cronin, T.W. (1996). Behavioural evidence for colour vision in stomatopod crustaceans. Journal of Comparative Physiology A 179, 473-481.

Matsuda, K., Hasegawa, E. \& Wilder, N. (2011). Analysis of composition and absorption maximum of visual pigment, and quantity of visual pigment at representative stages in the whiteleg shrimp Litopenaeus vannamei. Nippon Suisan Gakkaishi 77, 682-684.
Meyers, S.P. \& Hagood, R.W. (1984). Flake diets and larval crustacean culture. Progressive Fish-Culturists 46, 225-229.

Miller, G.C. (1971). Commercial fishery and biology of the freshwater shrimp, Macrobrachium, in the lower St. Paul River, Liberia, 1952-53. Special Scientific Report Fisheries No. 626. National Marine Fisheries Service, U.S. Department of Commerce, Washington, D.C.

Miller, R., Owens, S.J. \& Rorslett, B. (2011). Plants and colour: flowers and pollination. Optics and Laser Technology 43, 282-294.

Moctezuma, M.A. \& Blake, B.F. (1981). Burrowing activity in Penaeus vannamei Boone from the Caimanero-Huizache Lagoon System on the Pacific coast of Mexico. Bulletin of Marine Science 31, 312-317.

Moller, T.H. (1978). Feeding behaviour of larvae and postlarvae of Macrobrachium rosenbergii (de Man) (Crustacea: Palaemonidae). Journal of Experimental Biology 35, 251-258.

Moore, P.A. \& Atema, J. (1991). Spatial information in the threedimensional fine structure of an aquatic odor plume. Biological Bulletin $181,408-418$

New, M.B. (2002). Farming freshwater prawns: a manual for the culture of the giant river prawn (Macrobrachium rosenbergii). FAO Fisheries Technical Paper no. 428. FAO, Rome, Italy.

Ogle, J.T. (1991). Standard conditions for captive maturation and reproduction of Penaeus vannamei based upon a survey. Gulf Research Report 8, 295-297.

Ogle, J.T. \& Beaugez, K. (1991). Food preference of Penaeus vannamei. Gulf Research Reports 8, 291-294.

Oliveira, D.N.D, Christofoletti, R.A. \& Barreto, R.E. (2015). Feeding behavior of crabs according to cheliped number. PLoS ONE 10(12), e0145121.

Okayi, R.G., Solomon, S.G., Ataguba, A.G. et al. (2013). Indigenous knowledge of shrimp and prawn species and fishing of the Benue and Nigeria river (middle-belt savannah)-Nigeria. Agriculture and Biology Journal of North America 4, 221-226.

Pérez-Farfante, L. (1969). Western Atlantic shrimp of the genus Penaeus. Fishery Bulletin 67, 461-591.

Pontes, C.S. \& Arruda, M.de F. (2005) Acesso ao alimento artiథcial e enchimento do trato digestivo de juvenis do camarão marinho Litopenaeus vannamei (Boone) (Crustacea, Decapoda, Penaeidae) durante as fases clara e escura do perí|odo de 24 horas. Revista Brasileira de Zoologia 22, 1039 1043.

Pontes, C.S., Arruda, M.F., Menezes, A.A.L. et al. (2006). Daily activity pattern of the marine shrimp Litopenaeus vannamei (Boone 1931) juveniles under laboratory conditions. Aquaculture Research 37,1001-1006.

Premke, K., Klages, M. \& Arenz, W.E. (2006). Aggregation of Arctic deepwater scavengers at large food falls: temporal distribution, consumption rates and population structure. Marine Ecology Progress Series 325, 121135 .

Primavera, J. H. \& Caballero, R.M.V. (1992). Light color and ovarian maturation in unablated and ablated giant tiger prawn Penaeus monodon (Fabricius). Aquaculture 108, 247-256.

Pudadera, R.A. \& Primavera, J.H. (1981). Effect of light quality and eyestalk ablation on ovarian maturation in Penaeus monodon. Kalikasan, The Philippine Journal of Biology 10, 231-240.

Rajkumar, P., Rollmann, S.M., Cook, T.A. et al. (2010). Molecular evidence for color discrimination in the Atlantic sand fiddler crab, Uca pugilator. Journal of Experimental Biology 213, 4240-4248.

Rhodes, R.J. (2000). Economics and business management. In: Freshwater Prawn Culture. The Farming of Macrobrachium rosenbergi (M.B. New \& W.C. Valenti, eds.), pp 369-392. Blackwell Science, Oxford, UK

Robertson, L., Lawrence, A.L. \& Castille, F.L. (1993). Effect of feeding frequency and feeding time on growth of Penaeus vannamei (Boone) Aquaculture and Fisheries Management 24, 1-6. 
Santos, A.D.A., López-Olmeda, J.F., Sánchez-Vázquez, F.J. et al. (2016). Synchronization to light and meal time of the circadian rhythms of selffeeding behavior and locomotor activity of white shrimps (Litopenaeus vannamei). Comparative Biochemistry and Physiology A 199, 54-61.

Sanudin, N., Tuzan, A.D. \& Yong, A.S.K. (2014). Feeding activity and growth performance of shrimp postlarvae Litopenaeus vannamei under light and dark condition. Journal of Agricultural Science 6, 103-109.

Schmidt, M. \& Mellon, D. (2011). Neuronal processing of chemical information in crustaceans. In: Chemical Communication in Crustaceans (T. Breithaupt \& M. Thiel, eds.), pp 123-147. Springer Science+Buisiness Media, Dordrecht Netherlands

Steullet, P., Dudar, O., Flavus, T. et al. (2001). Selective ablation of antennular sensilla on the Caribbean spiny lobster Panulirus argus suggests that dual antennular chemosensory pathways mediated odorant activation of searching and localization of food. Journal of Experimental Biology 204, 4259-4269.

Tacon, A.G.J. (2002). Thematic review of feed and feed management practices in shrimp aquaculture. Report Prepared under the World Bank, NACA, WWF and FAO Consortium Program on Shrimp Farming and the Environment. Published by the Consocium

Tantikitti, C. (2014). Feed palatability and the alternative protein sources in shrimp feed. Songklanakarin Journal of Science and Technology 36, 51-55.

Theon, H.H., How, M.J., Chiou, T.H. et al. (2014). A different form of color vision in mantis shrimp. Science 343, 411-413.

Thurstone, L.L. (1927). A law of comparative judgment. Physiological Review 34, 272-286.

Tidwell, J.H. \& Coyle, S.D. (2008). Impact of substrate physical characteristics on growout of freshwater prawn, Macrobrachium rosenbergii, in ponds and pond microcosm tanks. Journal of the World Aquaculture Society 39, 406-413.

Tiews, K., Bravo, S.A. \& Ronquillo, I.A. (1968). On the food and feeding habits of some Philippine shrimps in Manila Bay and San Miquel Bay. Proceedings of Indo-Pacific Fisheries Council 13, 85-92.

Varadharajan, D. \& Pushparajan, N. (2013). Food and feeding habits of aquaculture candidate a potential crustacean of Pacific white shrimp Litopenaeus vannamei, southeast coast of India. Journal of Aquaculture Research and Development 4,161 doi:10.4172/2155-9546.1000161

von Frisch, K. (1950). Bees: Their Vision, Chemical Senses, and Language. Cornell University Press, 119 pp. Ithaca, New York, USA

Wang, F., Dong, S., Dong, S. et al. (2004). The effect of light intensity on the growth of Chinese shrimp Fenneropenaeus chinensis. Aquaculture 234, 475-483.

Wang, F., Dong, S., Dong, S. et al. (2003). The effect of light color on the growth of Chinese shrimp Fenneropenaeus chinensis. Aquaculture 228, 351-360.

Williams, K.C. (2007). Feed development for post-larval spiny lobster: a review. Bulletin of Fisheries Research Agency 20, 25-37.

Wurts, W.A. \& Stickney, R.R. (1984). An hypothesis on the light requirements for spawning penaeid shrimp, with emphasis on Penaeus setiferus. Aquaculture 41, 93-98.

Yacoob, S.Y. (2003). Attractants basics. Compounds enhance identification, consumption of aquafeed. Global Aquaculture Advocate April 2003, 46-47.

Yasharian, D., Coyle, S. D., Tidwell, J. H. et al. (2005). The effect of tank colouration on survival, metamorphosis rate, growth and time to metamorphosis freshwater prawn (Macrobrachium rosenbergii) rearing. Aquaculture Research 36, 278-283.

You, K., Yang, H., Liu, Y. et al. (2006). Effects of different light sources and illumination methods on growth and body color of shrimp Litopenaeus vannamei. Aquaculture 252, 557-565. 